\title{
Patterns of Overkill in Sexual Homicides
}

Julien Chopin (Ph.D) \& Eric Beauregard (Ph.D)

Chopin, J., Beauregard. E., (2020). Patterns of Overkill in Sexual Homicides. Journal of Criminal Psychology 


\section{Patterns of Overkill in Sexual Homicides}

\section{Introduction}

Sexual homicide is a hybrid type of crime combining the act of murder with acts of a sexual nature (Beech et al., 2005; Meloy, 2000; Myers, 2002; Porter et al., 2003). Despite the fact that sexual homicides are often described as "unusual", studies show that these crimes are highly heterogeneous in terms of offender characteristics and crime-commission processes (Higgs, Carter, Tully, et al., 2017). While the combination of sexual elements with the commission of a murder is frightening in itself, studies have shown that there is a gradation in the level of violence used in sexual homicide, with the commission of specific acts such as the insertion of foreign objects (Koeppel et al., 2019; Labuschagne \& Theron, 2008), necrophilic behaviors (Higgs, Carter, Stefanska, et al., 2017; Stein et al., 2010), dismemberment of the victim's body (Chopin \& Beauregard, in press-a), as well as the mutilation of the victim's body parts (Sea \& Beauregard, 2019). Among the behaviors described as unusual, overkill is another behavior that has rarely been empirically investigated in relation to sexual homicide. Studies conducted in different countries indicate that the rate of overkill varies between 29.89\% to 43.10\% (Beauregard \& Martineau, 2013, 2016; Chopin \& Beauregard, 2019a; Darjee \& Baron, 2013; Mjanes et al., 2017). Based on studies conducted by the FBI on a small group of sexual murderers, overkill has been associated with a disorganized process driven by impulsivity and motivated by anger (see Ressler et al., 1988). Although this assumption has been reported in several studies, it has never been empirically tested (Keppel \& Walter, 1999; Miller, 2014; Radojević et al., 2013; Solarino et al., 2019). Moreover, findings from recent studies have also suggested that overkill may ultimately be a behavior associated with an organized process in sexual homicide (Beauregard \& Martineau, 2016; Mjanes et al., 2017; Stefanska \& Carter, 2019; Stefanska et al., 2018). Given the conflicting view on the status of overkill and the lack of empirical research on this particular behavior, 
the aim of this study is to examine patterns of sexual homicide in which overkill has been observed. Specifically, this study aims to determine (1) whether overkill is a valid indicator of an organized or disorganized process and (2) whether overkill can be associated with different patterns of sexual homicide.

\section{Operationalization of Overkill}

Operationalization of overkill is not an easy task and there is much debate about the best method to determine its presence (see Trojan et al., 2019 for an exhaustive overview on this question). Most studies focusing on sexual homicide (Balemba et al., 2014; Beauregard \& Martineau, 2013, 2016; Mjanes et al., 2017; Solarino et al., 2019) used the FBI definition, which considers overkill as "the infliction of more injury than is necessary to kill a person" (Ressler et al., 1988, p. 55). Trojan et al. (2019) noted that this definition presents several issues. First, they raised the question as to whether the offender needed to be aware that he committed overkill. Second, Trojan et al. (2019) noted that there are no criteria to quantify the severity of the wounds. To overcome these limitations, several studies based on non-sexual homicide samples made an attempt to provide a more objective definition (e.g., Jordan et al., 2010; Salfati, 2003; Tamsen et al., 2015). For instance, Jordan et al. (2010, p. 187) suggested that overkill could be defined when a victim present "multiple injuries within one or more causes of death (i.e. multiple gunshot wounds) or if the multiple wounds of the same type were distributed over two or more body regions and considered causes of death in each". Tamsen et al. (2015, p. 95) stated that overkill is present when there are "a total of 40 or more skin injuries (blunt, sharp, gunshot) [or] 3 or more sharp wounds located at the head, neck, or trunk with internal organ injuries (including the pleura or large blood vessels) [or] three or more gunshot wounds located at the head, neck, or trunk with internal organ injuries (including the pleura and large blood vessels)". Although these definitions have provided a much more objective approach with clearer criteria, they also present significant 
shortcomings. First, they failed to provide a theoretical basis for the criteria they suggested. Second, these definitions are based on analysis of non-sexual homicide cases. Recent research found that when compared with non-sexual homicide, sexual homicide presents a very distinct type of crime (Chopin \& Beauregard, 2019c; Sea \& Beauregard, 2017) with specific crime-commission processes and motivations. Therefore, it was decided to use the FBI definition of overkill in this study.

\section{Overkill in Sexual Homicide}

Only a few studies have investigated the presence of overkill in the crime-commission process of sexual homicide. Moreover, inconsistencies have been identified in these few studies. Although some studies have associated overkill with a disorganized process, most recent studies have suggested instead that it could be related to an organized process as well. Originally, overkill was a behavior that the FBI had associated with a disorganized offender (Ressler et al., 1988). Disorganized offenders are known to present a chaotic and nonsophisticated crime-commission process by perpetrating violent, impulsive, and spontaneous attacks, using a coercive approach strategy (i.e., blitz attack) against acquaintances or randomly selected victims. These offenders are also characterized by the commission of ritualized behaviors based on fantasies, excessive mutilation of the breasts and genitals, as well as postmortem sexual activities (Douglas et al., 2013; Hazelwood \& Douglas, 1980; Ressler et al., 1988; Ressler et al., 1986). Douglas et al. (2013) highlighted that the presence of overkill behaviors in disorganized sexual homicide was motivated by the victim's depersonalization as well as the emotional intensity at the time of the crime (Keppel \& Walter, 1999; Miller, 2014; Radojević et al., 2013). This hypothesis has been reported in several studies (Miller, 2014; Radojević et al., 2013; Sewall et al., 2013; Solarino et al., 2019). 
More recently, this association was questioned as the results of several empirical studies suggested that overkill was more likely to be associated with an organized process (Beauregard \& Martineau, 2016) as well as to one of its sub-categories: the sadistic sexual murderer (Chopin \& Beauregard, 2020; Reale et al., 2017, 2020). The anger-retaliatory rape murderer identified by Keppel and Walter (1999) presented evidence of overkill and match the organized crime-commission process. According to the authors, these offenders planned both the sexual assault and the overkill (Keppel \& Walter, 1999). In these cases, the overkill is motivated by anger against a woman who belittles, humiliates, and rejects the offender. Similarly, Mjanes et al. (2017) have revisited the organized/disorganized classification and showed that overkill was more likely to be associated with the controlled (i.e., organized) instead of impetuous (i.e., disorganized) sexual murderer. These offenders were also more likely to control their victims, use a con strategy as their method of approach, and to penetrate the victim (Mjanes et al., 2017).

Organized sexual murderers are known to be more likely to use specific strategies to try to avoid police detection (Douglas et al., 2013; Hazelwood \& Douglas, 1980; Ressler et al., 1988; Ressler et al., 1986). Beauregard and Martineau (2016) tested this assumption and added overkill behavior as a characteristic of the organized crime-commission process. They found a positive relationship between the evidence of overkill and the ability to delay police detection. This finding suggested that some organized sexual murderers perpetrated overkill to prevent the identification of the victim's identity (Beauregard \& Martineau, 2016). Moreover, previous studies suggested that overkill in sexual homicide is not always the outcome of anger and impulsivity (Radojević et al., 2013; Stefanska et al., 2018). Stefanska et al. (2018) identified that a high level of violence could also be associated with both direct (i.e., the killing was a source of sexual stimulation) and indirect (i.e., the killing was not a 
source of sexual stimulation) sexual homicides, while Radojević et al. (2013) noted that overkill could be associated with sexual sadism.

\section{Aim of Study}

The literature on overkill in sexual homicide highlights two main points. First, only a few studies have examined empirically overkill behavior in sexual homicide. Second, it is unclear whether the presence of overkill is associated with an organized or a disorganized pattern of sexual homicide. Therefore, the purpose of this study is to provide a more in-depth examination on the presence of overkill in cases of sexual homicide. Specifically, this study attempts to answer the following two questions:

1. Is overkill a valid indicator of the organized or the disorganized sexual homicide?

2. Can overkill be associated with different patterns of sexual homicide?

\section{Methods}

\section{Sample}

Data used in this study come from the Sexual Homicide International Database (SHIelD). This database includes offender, victim, and crime characteristics of 762 solved (i.e., cases for which police investigators identified and charged a suspect) and unsolved (i.e., where an offender has not been identified by investigators) cases of extrafamilial (i.e., stranger or acquaintance relationships) sexual homicides that were committed in France and Canada between 1948 to 2018. The data were collected in Canada and France with exactly the same tool created to reference information on victims, offenders, and the crime-commission process with a total of 126 variables. The data included in the database come from various sources of information (e.g., investigative reports, offender interview reports, autopsy reports provided by pathologists, psychological reports provided by a team of forensic psychologists, and reports provided by forensic experts) and were compiled by crime analysts expert in violent crimes. The definition from Ressler et al. (1988) was used to identify cases of sexual 
homicide. To be considered as sexual, a homicide had to present at least one of the following characteristics at the crime scene: victim's attire or lack of attire; exposure of the sexual parts of the victim's body; sexual positioning of the victim's body; insertion of foreign objects into the victim's body cavities; evidence of sexual intercourse; evidence of substitute sexual activity, interest, or sadistic fantasy. As the FBI definition has been criticized for potentially presenting false positives (see Beauregard \& Martineau, 2017; Kerr, Beech, \& Murphy, 2013; Stefanska, Beech, \& Carter, 2016), all cases included in SHIelD present at least two criteria of the sexual homicide definition.

For this study we selected a sample of 662 solved cases of non-serial sexual homicide including $145 \mathrm{SH}$ cases where overkill was identified by coroners, crime investigators, and criminal analysts. Overkill was operationalized using the Ressler et al.'s (1988, p.55) definition (i.e., infliction of more injury than is necessary to kill a person). This method of identifying overkill was used because it not only corresponds to the definition used by crime analysts who coded the cases included in this study, but it also allows for more reliable crosscomparisons between other studies of sexual homicide, because this has been the most consistent definition used. The presence of overkill was determined based on medicolegal autopsy (i.e., diagnosis made considering excessive trauma beyond that necessary to cause death) as well as from interviews with the offenders. One of the major problems in studying overkill in sexual homicide is to determine whether this behavior was not confused with other similar behaviors. In order to test this aspect, we analyzed the correlations between overkill and other behaviors associated with the use of excessive violence in sexual homicide: 1) mutilation (i.e., the removal or irreparable disfigurement, by any means, of some smaller portion of one of those larger sections), 2) dismemberment (i.e., entire removal, by any means, of a large section of the body of a living or dead person, specifically, the head, arms, hands, torso, pelvic area, legs, or feet), 3) extreme acts committed on/with victim's body (i.e., 
carving on victim, evisceration, skinning victim), and 4) biting victim's body. There was no correlation between overkill and any of these extreme behaviors ${ }^{1}$.

\section{Measures}

Dependent variable. We used one dichotomous variable to distinguish sexual homicide cases with and without evidence of overkill $(0=$ absence; $1=$ presence $)$.

Independent variable. To test whether overkill is a characteristic of organized or disorganized sexual homicide, we used a total of 21 independent variables (20 dichotomous and one continuous). All of these variables are characteristics of the organized/disorganized sexual homicide and have been identified through several of the FBI studies (Douglas et al., 2013; Hazelwood \& Douglas, 1980; Ressler et al., 1988; Ressler et al., 1986) as well as studies who recently empirically tested the organized/disorganized classification (Beauregard \& Martineau, 2016; Mjanes et al., 2017). This study examines three offender variables coded dichotomously $(0=$ no; $1=$ yes $)$ : 1$)$ offender is married/in a relationship, 2$)$ offender had an active social life (i.e., participates in social situations and attends events where other people, including acquaintances and strangers, gather), 3) offender used alcohol prior to crime. These three variables are associated with organized murderers that are more likely to be "socially competent", "to use alcohol during the crime" and to be "living with a partner" (Ressler et al., 1988, p. 122). Organized sexual murderers are also known to target stranger victims in vulnerable situations (Douglas et al., 2013; Hazelwood \& Douglas, 1980; Ressler et al., 1988; Ressler et al., 1986). We used six variables to test this assumption: 4) victim and offender were strangers (i.e., did not know each other at the time of the offense), 5) victim was a female, 6) victim was less than 16 years old, 7) victim used alcohol/drugs prior to crime, 8) victim was frequently engaged in social activities, 9) victim was a sex trade worker. Moreover, 11 variables related to organized behaviors in sexual homicide were examined.

\footnotetext{
${ }^{1}$ Results are available upon request to the first author.
} 
These variables were all mentioned as criteria of organized sexual murderers by the FBI as well as from recent empirical studies (Beauregard \& Martineau, 2016; Douglas et al., 2013; Hazelwood \& Douglas, 1980; Mjanes et al., 2017; Ressler et al., 1988; Ressler et al., 1986): 10) offender targeted the victim, 11) offender used a con approach (i.e., as opposed to a coercive approach strategy; e.g., befriended the victim, posed as an authority figure, offered assistance, etc.), 12) offender used restraints (i.e., used to restrain the victim and not for sexual purposes), 13) offender beat the victim, 14) diverse sexual acts were perpetrated $[\mathrm{M}=$ 1.69; $\mathrm{SD}=1.53 ;$ Range $=0-5]$ (i.e., anal/vaginal penetration with a penis, digital penetration, foreign object insertion, fellatio, masturbation), 15) sexual sadism (SADSEX-SH scale was used to operationalize the concept of sexual sadism, for more details see Myers et al., 2019)2, 16) offender used a weapon, 17) offender took items from the victim, 18) offender used detection avoidance strategies (i.e., specific strategies to try to avoid police detection such as destruction of forensic evidence, protection of identity, see for example Beauregard \& Martineau, 2014; Chopin et al., 2020; Davies, 1992), 19) offender moved the victim's body (i.e., victim's body was moved from the crime scene to another location), 20) offender concealed victim's body, 21) offender selected deserted crime location.

\section{Analytical Strategy}

This study followed a three-step process. First, at the bivariate level (i.e., chi-square analysis, Mann-Whitney U test), we examined the differences between sexual homicide cases with and without evidence of overkill using the set of independent variables. Second, using only the significant variables $(\mathrm{p} \leq 0.05)$ from the bivariate analyses, we computed a binomial regression. The goal of this multivariate analysis was to identify the independent variables associated with overkill behaviors while taking into account the other variables. Multicollinearity was checked for the variables included in the multivariate analyses and no

\footnotetext{
${ }^{2}$ The SADSEX-SH is a scale used to assist in the diagnostic of sexual sadism from crime scene actions
} 
VIFs were above 1.165 while tolerance values were not below 0.859 . We also conducted a power analysis to determine whether the sample size was appropriate, we found no power values were below 0.801 and all were significant at $\mathrm{p} \leq 0.05$.

The third step of this study was to test the heterogeneity in the sample of 145 cases where overkill was identified. To this end, we used latent class analysis (LCA) in order to detect underlying patterns in a set of data or subgroups of individuals who share important behavioral characteristics (Collins \& Lanza, 2010). The goal of this procedure is to identify mutually exclusive classes using dichotomous variables (Collins \& Lanza, 2010; Lanza et al., 2007; Lanza et al., 2003). LCA is similar to cluster analysis but provides stronger models as it attributes class membership probabilities to each individual case. Seven models were computed and analyzed from a one-to-seven class solutions (Appendix 2). Several fit measures were used to identify the model: Bayesian Information Criterion (BIC), log likelihood, likelihood ratio $\mathrm{L}^{2}$, degrees of freedom, Akaike Information Criterion (AIC) and entropy. While LCA models are generally computed with only dichotomous variables, Dayton and Macready (2002) noted that it is possible to create models with mixed types of variables. The model was computed using variables that were identified in previous studies and that allowed to differentiate sexual homicide involving overkill. Previous studies suggested that sexual murderers who committed overkill were more likely to assault acquaintances and specifically targeted their victims for revenge purpose (Keppel \& Walter, 1999; Solarino et al., 2019). These offenders were also more likely to use a coercive approach (i.e., blitz) instead of a ruse, to use a weapon, and to beat their victims (Beauregard \& Martineau, 2016; Douglas et al., 2013; Hazelwood \& Douglas, 1980; Mjanes et al., 2017; Ressler et al., 1988; Ressler et al., 1986). As to the sexual acts, studies indicated that sexual homicides characterized with overkill were less likely to present a large number of sexual acts with the victims (Keppel \& Walter, 1999), while in some cases, overkill could be associated 
with sexual sadism (Douglas et al., 2013; Radojević et al., 2013). Finally, studies identified that sexual murderers who perpetrated overkill were more likely to use detection avoidance strategies (Beauregard \& Martineau, 2016; Mjanes et al., 2017).

We used a total of six dichotomous $(0=$ no; $1=$ yes $)$ variables and two continuous variable: 1) victim and offender were strangers (i.e., as opposed to acquaintance relationship), 2) offender used a con as a strategy to approach the victim (i.e., as opposed to coercive approach), 3) victim specifically targeted by the offender, 4) weapon intentionally used, 5)

victim was beaten, 6 ) diversity of sexual acts perpetrated (continuous) $[\mathrm{M}=1.29 ; \mathrm{SD}=1.17$; Range $=0-5]$ 7) Sexual sadism (SADSEX-SH scale), 8) offender used detection avoidance strategies. Multicollinearity was checked for the variables included in the LCA and no VIFs were above 1.115 and tolerance not below 0.897 .

\section{Results}

\section{Bivariate Analyses}

Table 1 presents findings on the comparisons between cases of sexual homicide with and without evidence of overkill. As to offender characteristics, results indicate that sexual homicide cases with overkill were more likely to involve offenders with an active social life $\left(\chi^{2}=34.63, \mathrm{p}=.000\right)$

As to victim characteristics, cases with overkill were less likely to involve victims who did not know their offenders $\left(\chi^{2}=22.12, \mathrm{p}=.000\right)$. However, the presence of overkill was associated with victims who had an active social life $\left(\chi^{2}=4.41, \mathrm{p}=.001\right)$ as well as victims who were often involved in social activities $\left(\chi^{2}=4.41, \mathrm{p}=.036\right)$.

As to the crime characteristics, cases of overkill were more frequently associated with cases were victims were not targeted by the offender $\left(\chi^{2}=9.17, \mathrm{p}=.050\right)$, when a con strategy was not used to approach the victims $\left(\chi^{2}=8.74, \mathrm{p}=.003\right)$, when restraints were not used $\left(\chi^{2}=6.89, p=.009\right)$, and when offenders had less diverse sexual acts $(U=31284, p=$ 
$.002, \mathrm{r}=.12)$. However, cases with overkill were associated more with cases that involved the beating of the victim $\left(\chi^{2}=11.21, p=.001\right)$, the use of a weapon $\left(\chi^{2}=22.04, p=.000\right)$, and moving the victim's body from the crime location $\left(\chi^{2}=3.99, \mathrm{p}=.056\right)$.

\section{[INSERT TABLE 1 HERE]}

\section{Binomial Regression}

Table 2 presents findings of the binomial regression. Findings show that sexual murderers with an active social life $(\beta=0.95, \mathrm{p}=.000)$ were more likely to perpetrate overkill. Sexual homicides where the victims were specifically targeted $(\beta=-0.60, p=.015)$ and totally unknown to the offenders $(\beta=-0.89, p=.000)$ were less likely to present evidence of overkill. Offenders who used a con strategy to approach the victim $(\beta=-0.52, p=.0 .12)$, who used restraints to overcome the victim's resistance $(\beta=-0.70, p=.020)$, and who committed more diverse sexual acts $(\beta=-0.18, \mathrm{p}=.024)$ were less likely to perpetrate overkill. Offenders who beat their victims $(\beta=-0.58, \mathrm{p}=.005)$, used a weapon $(\beta=-0.71, \mathrm{p}=$ $.003)$, and moved the victim's body from the crime location $(\beta=-0.43, p=.050)$ were more likely to perpetrate overkill.

\section{[INSERT TABLE 2 HERE]}

\section{Latent Class Analysis}

To determine patterns of overkill in sexual homicide, we used 8 variables related to crime characteristics. To assess the best latent class model, one-to-seven solutions were computed. It appeared that the 3-class solution was the best fitting class solution according to the BIC (Table 3). Up to class 3, BIC decreased, while from class 4 onward BIC started to increase. A smaller BIC suggests that the trade-off between fit and parsimony was achieved. Entropy for the 3-class solution was high $(0.84)$ and suggested that predictors used are fit to classify the cases and that classes were sufficiently distinct (Schwartz, 1978). 
Table 4 describes the 3 -class solution representing the three different sexual homicide patterns involving overkill. The largest class corresponds to class 1 including $68.28 \%$ of the cases, while the smallest is class 3, which includes $13.79 \%$ of the cases.

In class 1 , offenders and victims were less likely to be strangers $(0.26)$, offenders were more likely to use a con approach (0.28), and to specifically target a victim (0.14). Offenders were more likely to intentionally use a weapon (0.74) while they were less likely to beat the victim $(0.35)$ and to be sexual sadists $(0.26)$. They perpetrated on average 1.62 sexual acts during the crime and were less likely to use detection avoidance strategies (0.05).

In class 2 , offenders were more likely to assault unknown victims (missing value here), to use a con as a strategy to approach the victim (0.92), to beat the victim (0.68), and to intentionally use a weapon (0.73). Findings show that they were more likely to be sexual sadists (0.77) and less likely to specifically target a victim (0.00). This class of offenders committed on average 2.55 sexual acts and were more likely to use detection avoidance strategies (0.96).

In class 3 , offenders were less likely to be stranger to the victims $(0.05)$ and to be sexual sadists $(0.23)$. These offenders were more likely to use a con as a strategy to approach the victim $(0.75)$, to specifically target their victim $(0.85)$, to intentionally use a weapon (0.95), and to beat their victims (0.80). They perpetrated on average 1.22 sexual acts and were more likely to use detection avoidance strategies $(0.75)$.

\section{[INSERT TABLE 3 HERE]}

[INSERT TABLE 4 HERE]

\section{Discussion}

The current study investigated the presence of overkill in sexual homicide with two main objectives. First, we aimed to determine whether overkill is a specific feature of organized or disorganized sexual homicides. Second, we tested whether overkill could be present in 
various patterns of sexual homicide. Our findings indicated that overkill is associated to both organized and disorganized characteristics of sexual homicide. Moreover, classification analyses suggested that overkill was in fact associated with three distinct classes of sexual homicide.

\section{Overkill is an Indicator of both Organized and Disorganized Sexual Homicide}

Findings from the multivariate analyses suggested that overkill is associated with both organized and disorganized sexual homicides. Table 5 summarizes the main findings. Of the nine variables that remained significant at the multivariate level, four had a positive association with the organized crime-commission process, while the other five were associated with a disorganized crime-commission process (i.e., negative associations with organized process). These findings are congruent with previous findings suggesting that overkill is associated with a disorganized (Miller, 2014; Radojević et al., 2013; Ressler et al., 1988; Sewall et al., 2013; Solarino et al., 2019) and organized sexual murderers (Beauregard \& Martineau, 2016; Mjanes et al., 2017).

More specifically, our findings indicated that overkill was positively associated with characteristics of an organized sexual murderer, such as being socially competent, being more likely to beat the victim, use a weapon, and to try to delay/avoid police detection by moving the victim's body from the crime location. These characteristics match the anger-retaliatory rape murderer described by Keppel and Walter (1999). Sexual murderers included in this category planned both the rape and the overkill murder. For these offenders, the overkill is part of the crime-commission process and is motivated by the need for revenge and power against an unsuspecting substitute victim who replaces the initial source of the offender's anger (e.g., wife, mother, female supervisor, etc.) (Keppel \& Walter, 1999). However, we also found that overkill could be associated with a disorganized sexual homicide, such as targeting acquaintance victims, using coercive strategies of approach, not using restraints to overcome 
the victim's resistance, and the perpetration of less diverse sexual acts. These characteristics are in line with the power-reassurance rape murderer category identified by Keppel and Walter (1999). Offenders included in this category did not plan the death of the victim and overkill occurred due to panic, failure of the rape-assault, or rejection from the victim (Keppel \& Walter, 1999). This overkill pattern suggested the presence of uncontrolled violence associated with a feeling of anger and emotional intensity (Radojević et al., 2013). These results suggest that overkill is not a behavior specific to either category, but that it can be committed in both organized and disorganized homicides. As discussed by several authors, the presence of an excessive level of violence should not necessarily be associated with uncontrolled and impulsive behavior from the offender (Radojević et al., 2013; Stefanska et al., 2018). Stefanska et al. (2018) found that an excessive level of violence could also be associated with direct sexual homicides (i.e., the killing was a source of sexual stimulation), while Radojević et al. (2013) noted that it could be associated with sadistic acts. Our findings suggested that it could occur in both planned and organized crime-commission process as well as in a disorganized, unplanned, and impulsive homicidal process. Moreover, as suggested by Radojević et al. (2013), it can also be the outcome of a sadistic process. Overall, these findings suggest that the mere presence of overkill is not sufficient to classify a sexual homicide into a specific category. Overkill must be related to other elements of the criminal event to understand the entire crime-commission process and the underlying motivation behind it.

\section{[INSERT TABLE 5 HERE]}

\section{Heterogeneity of Overkill Scenarios in Sexual Homicide}

The second objective of this study was to empirically determine whether overkill could be associated with various patterns of sexual homicide. Three distinct patterns were identified. 
Impulsive: In cases of impulsive overkill, offenders attacked an acquaintance they did not specifically target. They used a coercive approach (i.e., blitz approach), sexually assaulted the victim, and finally used a weapon that led to some overkill without using any strategies to delay/avoid police detection. As was identified in several studies (Keppel \& Walter, 1999; Solarino et al., 2019), victims of overkill are often known to the offender. Additionally, in this category, offenders did not specifically target their victims. As mentioned by Keppel and Walter (1999), in some situations, sexual murderers randomly target victims that act as a substitute to the source of their anger. In such cases, offenders may target someone close to them who share similar characteristics of the person who is the source of their anger. We can also assume that this is a situation where the offender sexually assaulted someone close to him but did not plan killing the victim (Keppel \& Walter, 1999). Panic during the sexual aggression, victim's resistance, and anger may explain the presence of overkill during the sexual homicide. Moreover, offenders used a violent approach and did not attempt to use strategies to avoid police detection, which is typical of the disorganized sexual murderers (Douglas et al., 2013; Ressler et al., 1988; Ressler et al., 1986). In such situations, it seems that overkill is associated with an impulsive and uncontrolled excess of violence perpetrated by offenders who left the crime scene immediately afterwards and without being aware of the evidence left behind.

Sadistic. In cases of sadistic overkill, offenders assaulted stranger victims, using a con strategy as their method of approach. They both used physical violence and a weapon against the victim and had a higher average diversity of sexual acts perpetrated. Moreover, these offenders were more likely to be considered as sadistic and to try to avoid police detection. These findings are congruent with previous studies focusing on organized sexual murderers (Beauregard \& Martineau, 2016; Douglas et al., 2013; Hazelwood \& Douglas, 1980; Mjanes et al., 2017; Ressler et al., 1988; Ressler et al., 1986) and sadistic sexual murderers (Chopin \& 
Beauregard, 2019b, 2020; Myers et al., 2019; Proulx et al., 2007; Reale et al., 2017).

Radojević et al. (2013) suggested that in some cases, the presence of an excessive level of violence could be due to the presence of sexual sadism instead of the offender's anger. The identification of this particular class of offenders confirms thist assumption, as well as the idea that both organized and disorganized sexual murderers can perpetrate overkill.

Several hypotheses can be suggested to explain the association between sexual sadism and overkill. First, as mentioned by previous studies (Chopin \& Beauregard, in press-b; Holmes, 2017; Keppel et al., 2005), some sadistic sexual murderers may be involved in picquerism. Picquerism is the paraphilia associated with the sexual gratification from the process of penetrating a human body such as cutting, biting or stabbing. The practice of picquerism to an extreme level (e.g., multiple stab wounds) can lead sadistic offenders to overkill. Second, sadistic sexual murderers are known to be forensically aware (e.g., use of detection avoidance strategies, see Balemba et al., 2014; Chopin et al., 2020; Reale et al., 2017; Reale et al., 2020). Douglas et al. (2013) suggested that sadistic sexual murderers could overkill their victims for the simple purpose of obscuring the victim's identity. Finally, it is possible that the presence of overkill in a sadistic crime-commission process is intended to depersonalize the victim and to shock those who will discover the body.

Personal. In cases of personal overkill, offenders assaulted acquaintances that they specifically targeted. They sexually assaulted and committed overkill using both excessive physical violence and weapons. These offenders also tried to avoid police detection. Contrary to offenders who commit impulsive overkill, offenders involved in personal overkill did not randomly select their victims. As mentioned in previous studies (Aldridge \& Browne, 2003; Schlesinger et al., 2010) overkill has been associated with a feeling of revenge (Keppel \& Walter, 1999). Moreover, findings indicated that offenders involved in personal overkill used a con strategy as their method of approach and used specific strategies to delay/avoid police 
detection. These two characteristics suggest the presence of an organized crime-commission process and we may hypothesize that both the sexual assault and overkill were planned by the offenders to execute revenge against a specific victim.

\section{Conclusion}

The current study investigated patterns of overkill in sexual homicide and examined two interconnected research questions. First, we aimed to determine whether overkill is a good indicator of an organized or disorganized sexual homicide. Our findings showed that overkill can be perpetrated by both organized and disorganized sexual murderers. Thus, disorganized sexual murderers were more involved in impulsive and unplanned overkill, while organized offenders were more likely to plan the overkill. This led us to the conclusion that the simple presence of overkill is not sufficient to determine the type of crime or offender. The entire criminal event must be analyzed - as well as the many interactions between the offender's behavior - to determine the degree of planning and correctly classify the offender. Second, since overkill could be detected in both organized and disorganized sexual homicides, we tested the various patterns of sexual homicide involving overkill. Using latent class analysis, we identified three distinct patterns of sexual homicide where overkill could be present: impulsive, sadistic, and personal. These findings showed that although overkill may seem as very extreme and unusual, this is a behavior that may be present in various crime-commission processes, suggesting that it could be motivated by very different purposes (e.g., feeling of revenge versus obscuring the victim's identity).

This study presents several implications. First, our findings indicate that the presence of overkill is not a valid indicator to determine the organized/disorganized patterns of a sexual homicide. The analysis must focus on a set of indicators to establish the level of planification. Thus, overkill should not be considered as an indicator of planning as has been suggested in some studies. Second, the results provide empirical evidence that overkill is one of the 
behaviors that can be perpetrated by sadistic sexual murderers. From an investigative perspective, criminal investigators should be aware that the presence of overkill does not refer to a single category of sexual homicide and that it is important to observe other crime scene behaviors to determine working hypotheses and suspect prioritization (e.g., use of weapons, use of detection avoidance strategies, sadistic process, etc.).

Although this study presents several new insights, it is not without limitations. First, although verifications have been made with coroners, police investigators, and crime analysts on the basis of forensic reports and offenders interviews, we cannot exclude the possibility that some cases classified as overkill may have been in fact the result of underkill (i.e., offender was not effective in his killing method and therefore had to inflict a large number of wounds before finally killing the victim, Beauregard \& Martineau, 2013). Second, we cannot exclude the possibility of false positive for some cases where overkill was not identified and consequently not included in the sample we analyzed in this study. As mentioned by Trojan et al. (2019), cases of overkill with few injuries are less likely to be identified. Third, we analyzed only solved cases and it is possible that unsolved cases present a different crime pattern (e.g., overkill mainly aimed at avoiding or delaying the discovery of the victim's identity).

Further studies need to test the validity of this classification with cases from other countries. Research should focus on determining whether there are differences in the process of organized and disorganized overkill by analyzing both qualitative (e.g., location of injuries on the body, means used) and quantitative indicators (e.g., number of injuries) elements. Research should also focus on the phenomenon of underkill in order to find a way to differentiate it from overkill and to establish the crime patterns in which they occur. Finally, analysis of the association between sexual sadism and overkill need more investigation. It 
would be interesting to empirically determine whether overkill is part of the deviant sexual fantasies or if it is mainly related to avoiding detection strategies. 


\section{References}

Aldridge, M. L., \& Browne, K. D. (2003). Perpetrators of spousal homicide: A review. Trauma, Violence, \& Abuse, 4(3), 265-276.

Balemba, S., Beauregard, E., \& Martineau, M. M. (2014). Getting away with murder: a thematic approach to solved sexual homicides using crime scene factors. Police Practice and Research: An International Journal, 15(3), 221-233.

Beauregard, E., \& Martineau, M. M. (2013). A descriptive study of sexual homicide in Canada: Implications for police investigation. International Journal of Offender Therapy and Comparative Criminology, 57(12), 1454-1476.

Beauregard, E., \& Martineau, M. M. (2014). No body, no crime? The role of forensic awareness in avoiding police detection in cases of sexual homicide. Journal of Criminal Justice, 42(2), 213-220.

Beauregard, E., \& Martineau, M. M. (2016). Does the organized sexual murderer better delay and avoid detection. Journal of interpersonal violence, 31(1), 4-25.

Beech, A., Fisher, D., \& Ward, T. (2005). Sexual murderers' implicit theories. Journal of interpersonal violence, 20(11), 1366-1389. 
Chopin, J., \& Beauregard, E. (2019a). Sexual homicide in France and Canada: An international comparison. Journal of interpersonal violence, Advance online publication. https://doi.org/10.1177/0886260519875547

Chopin, J., \& Beauregard, E. (2019b). Sexual homicide: A criminological perspective. Current Psychiatry Reports, 21(12), 1-9. https://doi.org/10.1007/s11920-019-1107-z

Chopin, J., \& Beauregard, E. (2019c). The sexual murderer is a distinct type of offender. International Journal of Offender Therapy and Comparative Criminology, 63(9), 1597-1620. https://doi.org/10.1177/0306624X18817445

Chopin, J., \& Beauregard, E. (2020). Sexual sadism: Its role in the crime-commission process of sexual homicide of children Journal of interpersonal violence, Advance online publication. https://doi.org/10.1177/0886260520916844

Chopin, J., \& Beauregard, E. (in press-a). Body dismemberment in sexual homicide cases: Lust murder or rational decision? Psychology, Crime \& Law.

Chopin, J., \& Beauregard, E. (in press-b). Patterns of necrophilic behaviors in sexual homicide: A criminological perspective. International Journal of Offender Therapy and Comparative Criminology.

Chopin, J., Beauregard, E., \& Bitzer, S. (2020). Factors influencing the use of forensic awareness strategies in sexual homicide. Journal of Criminal Justice. 
Collins, L. M., \& Lanza, S. T. (2010). Latent class and latent transition analysis: With applications in the social, behavioral, and health sciences. Wiley.

Darjee, R., \& Baron, E. (2013). Sexual homicide: A comparison of homicidal and nonhomicidal sexual offenders. annual meeting of the Association of Treatment of Sexual Abusers, Chicago, IL,

Davies, A. (1992). Rapists' behaviour: A three aspect model as a basis for analysis and the identification of serial crime. Forensic Science International, 55(2), 173-194.

Dayton, M. C., \& Macready, G. B. (2002). Use of Categorical and Continuous Covariates in Latent Class Analysis. In J. A. Hagenaars \& A. L. McCutcheon (Eds.), Applied Latent Class Analysis (pp. 213-233). Cambridge University Press https://doi.org/10.1017/CBO9780511499531.009

Douglas, J., Burgess, A. W., Burgess, A. G., \& Ressler, R. K. (2013). Crime classification manual: A standard system for investigating and classifying violent crime. John Wiley $\&$ Sons.

Hazelwood, R. R., \& Douglas, J. (1980). The lust murderer. FBI Law Enforc Bull, 49, 1-5.

Higgs, T., Carter, A. J., Stefanska, E. B., \& Glorney, E. (2017). Toward identification of the sexual killer: A comparison of sexual killers engaging in post-mortem sexual interference and non-homicide sexual aggressors. Sexual Abuse, 29(5), 479-499. 
Higgs, T., Carter, A. J., Tully, R. J., \& Browne, K. D. (2017). Sexual murder typologies: A systematic review. Aggression and Violent Behavior, 35, 1-12.

Holmes, D. (2017). Psychology and Dismemberment. In S. Black, G. Rutty, S. V. Hainsworth, \& G. Thomson (Eds.), Criminal dismemberment: forensic and investigative analysis (pp. 27-39). CRC Press.

Jordan, C. E., Pritchard, A. J., Duckett, D., Wilcox, P., Corey, T., \& Combest, M. (2010). Relationship and injury trends in the homicide of women across the life span: A research note. Homicide Studies, 14(2), 181-192.

Keppel, R., Weis, J. G., \& Brown, K. (2005). The Jack the Ripper murders: a modus operandi and signature analysis of the 1888-1891 Whitechapel murders. Journal of Investigative Psychology and Offender Profiling, 2(2005), 1-21.

Keppel, R. D., \& Walter, R. (1999). Profiling killers: A revised classification model for understanding sexual murder. International Journal of Offender Therapy and Comparative Criminology, 43(4), 417-437.

Koeppel, S., Schlesinger, L. B., Craun, S. W., Keel, T. G., Rubin, D., \& Kum, J. (2019). Foreign Object Insertions in Sexual Homicide. International Journal of Offender Therapy and Comparative Criminology, 63(9), 1726-1737. 
Labuschagne, G., \& Theron, A. (2008). Foreign object insertion in sexual homocide: towards an offender profile. Acta Criminologica: African Journal of Criminology \& Victimology, 2, 117-128.

Lanza, S. T., Collins, L. M., Lemmon, D. R., \& Schafer, J. L. (2007). PROC LCA: A SAS procedure for latent class analysis. Structural equation modeling: a multidisciplinary journal, 14(4), 671-694.

Lanza, S. T., Flaherty, B. P., \& Collins, L. M. (2003). Latent class and latent transition analysis. In J. A. JSchinka \& W. F. Velicer (Eds.), Handbook of psychology: Vol. 2 Research methods in psychology (pp. 663-685). Wiley.

Meloy, J. R. (2000). The nature and dynamics of sexual homicide: An integrative review. Aggression and Violent Behavior, 5(1), 1-22. https://doi.org/10.1016/S13591789(99)00006-3

Miller, L. (2014). Serial killers: I. Subtypes, patterns, and motives. Aggression and Violent Behavior, 19(1), 1-11.

Mjanes, K., Beauregard, E., \& Martineau, M. M. (2017). Revisiting the organized/disorganized model of sexual homicide. Criminal Justice and Behavior, 44(12), 1604-1619.

Myers, W. C. (2002). Juvenile sexual homicide. Academic Press. 
Myers, W. C., Beauregard, E., \& Menard, W. (2019). An updated sexual homicide crime scene rating scale for sexual sadism (SADSEX-SH). International Journal of Offender Therapy and Comparative Criminology, 63(9), 1766-1775. https://doi.org/10.1177/0306624X19839595

Porter, S., Woodworth, M., Earle, J., Drugge, J., \& Boer, D. (2003). Characteristics of sexual homicides committed by psychopathic and nonpsychopathic offenders. Law and human behavior, 27(5), 459. https://doi.org/10.1023/A:1025461421791

Proulx, J., Blais, E., \& Beauregard, E. (2007). Sadistic Sexual Offenders. In J. Proulx, E. Beauregard, \& A. Nicole (Eds.), Sexual murderers: A comparative analysis and new perspectives (pp. 107-122). John Wiley \& Sons.

Radojević, N., Radnić, B., Petković, S., Miljen, M., Čurović, I., Čukić, D., Šoć, M., \& Savić, S. (2013). Multiple stabbing in sex-related homicides. Journal of forensic and legal medicine, 20(5), 502-507.

Reale, K., Beauregard, E., \& Martineau, M. M. (2017). Sadism in sexual homicide offenders: identifying distinct groups. Journal of criminal psychology, 7(2), 120-133. https://doi.org/10.1108/JCP-11-2016-0042

Reale, K., Beauregard, E., \& Martineau, M. M. (2020). Is investigative awareness a distinctive feature of sexual sadism? Journal of interpersonal violence, 35(7-8), 17611778. 
Ressler, R. K., Burgess, A. W., \& Douglas, J. (1988). Sexual homicide: Patterns and motives. Free Press.

Ressler, R. K., Burgess, A. W., Douglas, J. E., Hartman, C. R., \& D’Agostino, R. B. (1986). Sexual killers and their victims: Identifying patterns through crime scene analysis. Journal of interpersonal violence, 1(3), 288-308.

Salfati, C. G. (2003). Offender interaction with victims in homicide: A multidimensional analysis of frequencies in crime scene behaviors. Journal of interpersonal violence, $18(5), 490-512$.

Schlesinger, L. B., Kassen, M., Mesa, V. B., \& Pinizzotto, A. J. (2010). Ritual and signature in serial sexual homicide. Journal of the American Academy of Psychiatry and the Law Online, 38(2), 239-246.

Schwartz, G. (1978). Estimating the dimension of a model. The Annals of Statistics, 461-464.

Sea, J., \& Beauregard, E. (2017). An analysis of crime scene behavior in Korean homicide. Journal of interpersonal violence, 0886260517724832.

Sea, j., \& Beauregard, E. (2019). Mutilation in Korean homicide: An exploratory study. Journal of interpersonal violence, 34(14), 2863-2877.

Sewall, L. A., Krupp, D. B., \& Lalumière, M. L. (2013). A test of two typologies of sexual homicide. Sexual Abuse, 25(1), 82-100. https://doi.org/10.1177/1079063212452617 
Solarino, B., Punzi, G., Di Vella, G., Carabellese, F., \& Catanesi, R. (2019). A multidisciplinary approach in overkill: analysis of 13 cases and review of the literature. Forensic Science International, 298, 402-407.

Stefanska, E. B., \& Carter, A. J. (2019). Whiter than white: the art of delaying detection in sexual killers. International Journal of Offender Therapy and Comparative Criminology, 0306624X19840954.

Stefanska, E. B., Higgs, T., Carter, A. J., \& Beech, A. (2018). "We boil at different degrees": Factors associated with severity of attack in sexual killing. Journal of interpersonal violence, Advance online publication.

Stein, M. L., Schlesinger, L. B., \& Pinizzotto, A. J. (2010). Necrophilia and sexual homicide. Journal of Forensic Sciences, 55(2), 443-446.

Tamsen, F., Logan, F. K., \& Thiblin, I. (2015). Homicide injury quantification: correlations and reliability of injury severity scores applied to homicide victims. Homicide Studies, 19(1), 88-100.

Trojan, C., Salfati, C. G., \& Schanz, K. (2019). Overkill, we know it when we see it: examining definitions of excessive injury in homicide research. Journal of criminal psychology, 9(2), 61-74. https://doi.org/10.1108/JCP-09-2018-0040 


\section{Tables}

Table 1. Bivariate analysis $(\mathrm{N}=662)$

\begin{tabular}{|c|c|c|c|c|c|}
\hline & \multicolumn{2}{|c|}{$\begin{array}{c}\text { No overkill } \\
\mathrm{n}=517\end{array}$} & \multicolumn{2}{|c|}{$\begin{array}{c}\text { Overkill } \\
n=145\end{array}$} & \multirow{2}{*}{$\begin{array}{c}\chi^{2} \\
\text { Mann-Whitney U }\end{array}$} \\
\hline & $\mathrm{n}$ & $\%$ & $\mathrm{n}$ & $\%$ & \\
\hline \multicolumn{6}{|l|}{ Offender characteristics } \\
\hline Offender is married/in a relationship & 164 & 31.72 & 41 & 28.28 & 0.63 \\
\hline Offender had an active social life & 71 & 13.73 & 51 & 35.17 & $34.63 * * *$ \\
\hline Offender used alcohol previously to crime commission & 288 & 55.71 & 82 & 56.55 & 0.03 \\
\hline \multicolumn{6}{|l|}{ Victim selection } \\
\hline Victim and offender were strangers & 271 & 52.42 & 44 & 30.34 & $22.12 * * *$ \\
\hline Victim was a female & 436 & 84.33 & 126 & 86.90 & 0.58 \\
\hline Victim less than 16 years old & 101 & 19.54 & 35 & 24.14 & 1.47 \\
\hline Victim used alcohol/drugs prior to crime & 146 & 28.24 & 51 & 35.17 & 2.60 \\
\hline Victim was frequently engaged in social activities & 123 & 23.79 & 47 & 32.41 & $4.41 *$ \\
\hline Victim is a sex trade worker & 33 & 6.38 & 13 & 8.97 & 1.17 \\
\hline \multicolumn{6}{|l|}{ Crime characteristics } \\
\hline Offender targeted the victim & 179 & 34.62 & 31 & 21.38 & $9.17 * *$ \\
\hline Offender used a con approach & 310 & 59.96 & 67 & 46.21 & $8.74 * *$ \\
\hline Offender used restrains & 111 & 21.47 & 17 & 11.72 & $6.89 * *$ \\
\hline Offender beat the victim & 215 & 41.59 & 83 & 57.24 & $11.21 * * *$ \\
\hline Diversity of sexual acts perpetrated (continuous) & \multicolumn{2}{|c|}{$1.80[S D=1.60]$} & \multicolumn{2}{|c|}{$1.29[S D=1.17]$} & $31284 * *$ \\
\hline Sexual sadism (SADSEX-SH) & 149 & 28.82 & 50 & 34.48 & 1.73 \\
\hline Offender used a weapon & 325 & 62.86 & 111 & 76.55 & $9.44 * *$ \\
\hline Offender took items from the victim & 195 & 37.72 & 58 & 40.00 & 0.25 \\
\hline Offender used detection avoidance strategies & 292 & 56.48 & 82 & 56.55 & 0.00 \\
\hline Offender moved the victim's body & 138 & 26.69 & 51 & 35.17 & $3.99 *$ \\
\hline Offender concealed victim's body & 249 & 48.16 & 72 & 49.66 & 0.10 \\
\hline Offender selected less risky crime location & 140 & 0.27 & 48 & 33.10 & 2.02 \\
\hline
\end{tabular}

Notes. ${ }^{*} p \leqslant .05 . * * p \leqslant .01 . * * * p \leqslant .001$.

Table 2. Binomial regression predicting overkill $(\mathrm{N}=662)$

\begin{tabular}{llll} 
& $\beta$ & S.E. & $\operatorname{Exp}(\beta)$ \\
\hline Offender had an active social life & 0.944 & 0.248 & $2.571^{* * *}$ \\
Victim and offender were strangers & -0.891 & 0.221 & $0.410^{* * *}$ \\
Victim was frequently engaged in social activities & 0.048 & 0.237 & 1.050 \\
Victim specifically targeted & -0.599 & 0.247 & $0.547^{*}$ \\
Con approach & -0.521 & 0.208 & $0.594^{* *}$ \\
Use of restrains & -0.704 & 0.302 & $0.495^{*}$ \\
Victim was beaten & 0.584 & 0.206 & $1.793^{* *}$ \\
Diversity of sexual acts perpetrated (continuous) & -0.183 & 0.081 & $0.833^{*}$ \\
Offender used a weapon & 0.709 & 0.235 & $2.033^{* *}$ \\
Body moved & 0.434 & 0.222 & $1.544^{*}$ \\
\hline Constant & -1.447 & 0.291 & $0.235^{* * *}$ \\
$\chi 2$ & $94.249^{* * *}$ & & \\
-log likelihood & 601.753 & & \\
Hosmer and Lemeshow test & 10.826 & & \\
\hline Overall classification \% & 78.4 & & \\
\hline
\end{tabular}

Notes. $\dagger \mathrm{p} \leq .1 .{ }^{*} \mathrm{p} \leq .05 .{ }^{* *} \mathrm{p} \leq .01 . * * * \mathrm{p} \leq .001$. 
Table 3. Fit indices for latent classes.

\begin{tabular}{cccccc}
$\mathrm{Nb}$ of classes & LL & BIC(LL) & AIC(LL) & L $^{2}$ & Entropy \\
\hline 1-Cluster & -747.21 & 1529.26 & 1508.42 & 252.96 & 1 \\
2-Cluster & -722.64 & 1559.74 & 1491.28 & 203.82 & 0.88 \\
3-Cluster & $\mathbf{- 7 2 9 . 1 7}$ & $\mathbf{1 5 3 2 . 9 8}$ & $\mathbf{1 4 8 8 . 3 3}$ & $\mathbf{2 1 6 . 8 7}$ & $\mathbf{0 . 8 4}$ \\
4-Cluster & -717.05 & 1588.38 & 1496.10 & 192.64 & 0.83 \\
5-Cluster & -711.81 & 1617.72 & 1501.63 & 182.17 & 0.82 \\
6-Cluster & -706.89 & 1647.68 & 1507.78 & 172.32 & 0.79 \\
7-Cluster & -702.29 & 1678.30 & 1514.58 & 163.12 & 0.77 \\
\hline
\end{tabular}

Table 4. Profile of three latent classes - Mean probabilities of crime characteristics based on class membership

\begin{tabular}{lccc} 
Cluster size & $\begin{array}{c}\text { Class 1 } \\
\text { Disorganized } \\
\text { impulsive overkill }\end{array}$ & $\begin{array}{c}\text { Class 2 } \\
\text { Organized } \\
\text { sadistic overkill }\end{array}$ & $\begin{array}{c}\text { Class 3 } \\
\text { Organized } \\
\text { personal overkill }\end{array}$ \\
\cline { 2 - 4 } & 99 & 26 & 20 \\
\hline Victim and offender were strangers & $68.28 \%$ & $17.93 \%$ & $13.79 \%$ \\
Con approach & 0.26 & 0.77 & 0.05 \\
Victim specifically targeted & 0.28 & 0.92 & 0.75 \\
Weapon intentionally used & 0.14 & 0.00 & 0.85 \\
Victim was beaten & 0.74 & 0.73 & 0.95 \\
Diversity of sexual acts perpetrated (mean) & 0.35 & 0.68 & 0.80 \\
Sexual sadism (SADSEX-SH) & 1.62 & 2.55 & 1.22 \\
Offender used avoidance detection strategies & 0.26 & 0.77 & 0.23 \\
\hline
\end{tabular}

Table 5. Comparisons Between the Effects of Organized Behaviors on the overkill behavior

\begin{tabular}{lc}
\multicolumn{1}{c}{ Organized behaviors } & Overkill \\
\hline Offender had an active social life & Positive \\
Victim and offender were strangers & Negative \\
Victim specifically targeted & Negative \\
Con approach & Negative \\
Use of restrains & Negative \\
Victim was beaten & Positive \\
Diversity of sexual acts perpetrated & Negative \\
Offender used a weapon & Positive \\
Body moved & Positive \\
\hline
\end{tabular}

